\title{
A gastrointestinal stromal tumor presenting as a pelvic mass: A case report
}

\author{
ROBERTO ANGIOLI ${ }^{1}$, CLEONICE BATTISTA ${ }^{1}$, LUDOVICO MUZII ${ }^{1}$, \\ GIOVANNA MADONNA TERRACINA ${ }^{1}$, ESTER VALENTINA CAFÀ ${ }^{1}$, MARIA ISABELLA SERENI ${ }^{1}$, \\ ROBERTO MONTERA $^{1}$, FRANCESCO PLOTTI ${ }^{2}$, CARLA RABITTI $^{1}$ and PIERLUIGI BENEDETTI PANICI ${ }^{2}$ \\ ${ }^{1}$ Department of Obstetrics and Gynecology 'Campus Biomedico' University of Rome, Via Alvaro del Portillo 200, \\ 00128 Rome; ${ }^{2}$ Department of Obstetrics and Gynecology 'La Sapienza' University of Rome, \\ V.le del Policlinico 155, 00161 Rome, Italy
}

Received March 18, 2008; Accepted September 19, 2008

DOI: 10.3892/or_00000301

\begin{abstract}
Gastrointestinal stromal tumors (GISTs) represent $0.1-1 \%$ of gastrointestinal malignancies. They are commonly asymptomatic and found incidentally during laparoscopy, surgical procedures or radiological studies. Diagnosis is based on histology and immunohistochemistry, while the role of imaging studies is not diagnosis-specific. We present the case of a 38-year-old patient complaining of an increase in her abdominal circumference. Consequently, a vaginal examination, a transvaginal ultrasound and an MRI of the abdomen and pelvis were carried out. It should be noted that a preoperative diagnosis of GISTs is uncommon, due to the rarity and many presentations of the disease. Ultrasound and MRI are not able to differentiate a GIST from ovarian cancer. However, if a pelvic mass is detected, the possibility of a nongynaecological tumor has to be considered.
\end{abstract}

\section{Introduction}

Gastrointestinal stromal tumors (GISTs) represent $0.1-1 \%$ of gastrointestinal malignancies (1). They are the most common mesenchymal tumors of the gastrointestinal tract. Generally, they are asymptomatic and found incidentally during surgical procedures or radiological studies. When symptomatic, these tumors tend to present as GI bleeding, abdominal mass or abdominal pain (2).

GIST may arise anywhere in the tubular gastrointestinal tract from the oesophagus to the rectum $(3,4)$. Identical lesions may occur in extra-intestinal locations such as the mesentery, omentum and retroperitoneum, while exceptional sites are

Correspondence to: Dr Roberto Angioli, Department of Obstetrics and Gynecology 'Campus Biomedico' University of Rome, Via Alvaro del Portillo 200, 00128 Rome, Italy

E-mail: r.angioli@unicampus.it

Key words: pelvic mass, gastrointestinal stromal tumor, ovarian tumor include the gallbladder or bladder (5). In terms of distribution, $50-60 \%$ of lesions arise in the stomach, $20-30 \%$ in the small bowel, $10 \%$ in the large bowel, $5 \%$ in the oesophagus and $5 \%$ elsewhere in the abdominal cavity (5-7).

Diagnosis is based on histology and immunohistochemistry. In the past, GISTs were considered to be part of GI leiomyomas, leiomyosarcomas, leiomyoblastomas and the schwannomas group (Table I) as a result of their histological findings and apparent origin in the muscolaris propria layer of the intestinal wall. With the advent of immunohistochemical staining techniques and ultrastructural evaluation, GISTs are now recognized as a distinct group of mesenchymal tumors. They originate from the interstitial cell of Cajal, a cell type which shares immunophenotypical and ultrastructural features of muscle and neuronal cells. Moreover, $95 \%$ of GISTs show KIT (CID117) immunopositivity, which is a specific marker for the tumor. Aside from consistent positivity for KIT, $\sim 60-70 \%$ of GISTs show immunopositivity for CD34, 30-40\% for smooth-muscle actin (SMA) and 5\% for the S-100 protein.

As regards their development, $20-30 \%$ of GISTs show malignant behaviour. A large size and high mitotic activity have been strongly associated with malignancy, while very low risk is characterised by tumors $<2 \mathrm{~cm}$ and $<5$ mitosis $/ 50$ high power fields. Nevertheless, a small size and the absence of mitotic activity do not preclude malignant behaviour (8).

GISTs do not generally metastasize to the regional lymph node but spread hematogenously to the liver or metastasize to the peritoneum. However, despite appearing to lack mitotic activity, a few GISTs still metastasize. Due to this unpredictable behaviour, GISTs must be treated as potentially malignant. KIT is certainly the ideal target for such an innovative therapeutic approach as it has proven to be biologically relevant (9).

We report on a rare case of a large gastrointestinal stromal tumor, presented as a suspected pelvic mass, in a young female patient.

\section{Case report}

A 38-year-old woman was referred to our institution with a diagnosis of a pelvic mass suspicted as ovarian cancer. She 
Table I. Mesenchymal tumor classification.

Benign submucosal tumors Malignant submucosal tumors

Leiomyomas Leiomyosarcoma

Schwannomas

Gastrointestinal stromal tumors

Granular cell tumors

Heterotopic pancreatic

tissue

Lipomas

Neurofibromatosis

Vascular tumors

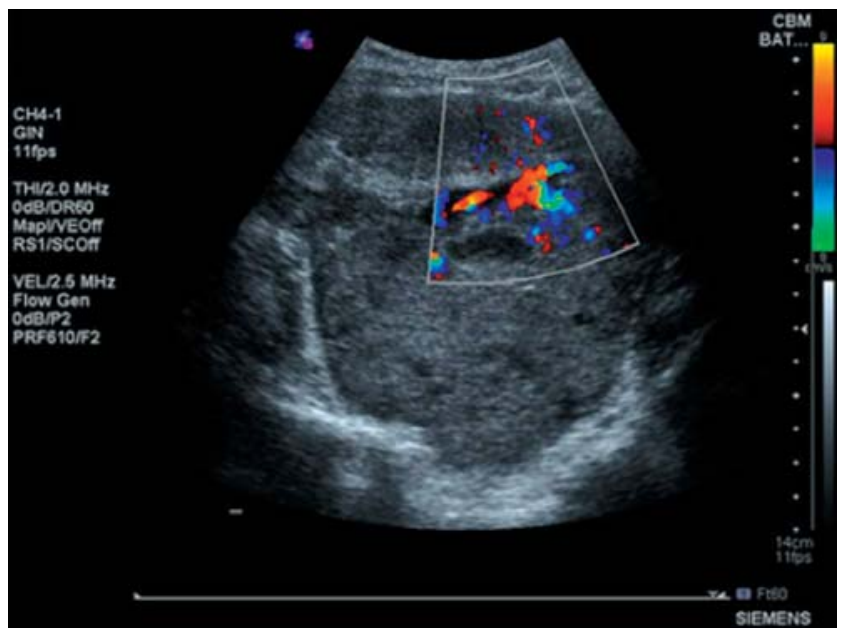

Figure 1. Transabdominal ultrasound of pelvis: heterogeneous and vascularised mass with predominantly solid component.

had observed an increase in abdominal circumference although no other symptoms were referred. Her past medical history was not significant except for an uncomplicated caesarean section 24 months earlier.

On pelvic examination, a large and compact pelvic mass extending to the periumbilical area was noted. A transvaginal ultrasound (Fig. 1) suggested a 160x88 mm heterogeneous and vascularised mass with predominantly solid components. The mass extended up to the umbilicus. The ovaries were not visible, the uterus was displaced anteriorly and there were no signs of ascites or metastasis. Due to the uncertain nature and origin of the mass, the patient underwent MRI of the abdomen and pelvis (Fig. 2) which showed a complex mass of $18 \times 7 \mathrm{~cm}$, occupying the pelvis. It appeared to be heterogeneous with necrotic areas originating from the peritoneum, while the uterus and bladder appeared dislocated anteriorly. The Ca125 value was $35.8 \mathrm{U} / \mathrm{ml}$. The patient underwent surgery for a pelvic mass with suspected malignancy.

During surgery a xypho-pubic incision was performed, and the abdominal cavity was opened. The pelvis appeared totally

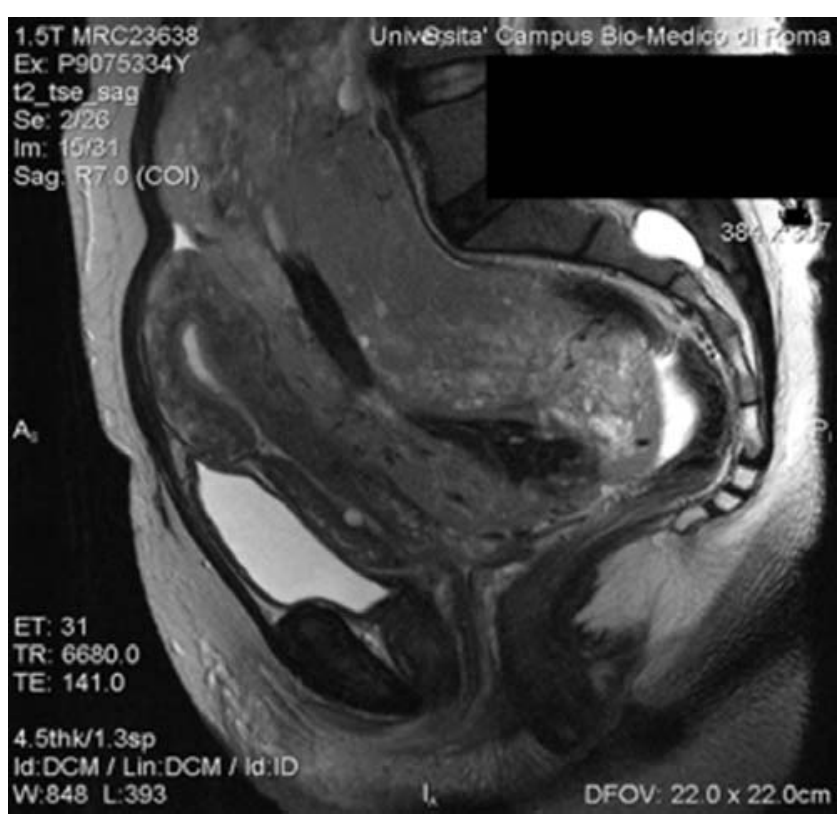

Figure 2. RMI pelvis: a complex mass occupying the pelvis. It appeared to be heterogeneous within the necrotic areas. The uterus and bladder appeared dislocated anteriorly.

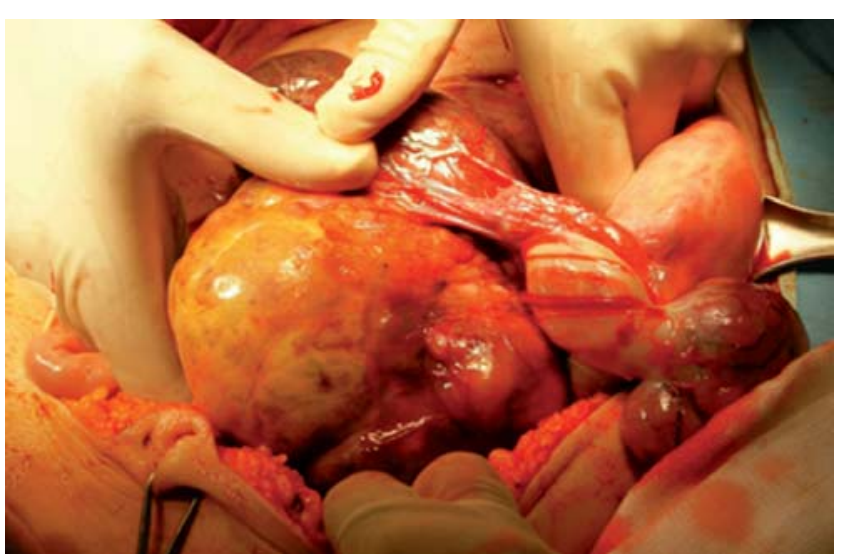

Figure 3. (Head of patient on the left) GIST at laparotomy showing adherence of the bowel to the mass.

occupied by a voluminous mass of apparently ovarian origin. The mass adhered to the small bowel, ovaries and posterior wall of the uterus (Fig. 3). The segment of small bowel attached to the mass was resected with the mass and a handsewn latero-lateral anastomosis was performed. Subsequently, the uterus, adnexa and mass with resected bowels were completely removed. The material was sent to pathology.

Macroscopically, the mass appeared white-grey, measured $17 \mathrm{~cm}$ and contained haemorrhagic and necrotic areas. A fragment of neoplastic tissue, similar to the mass, adhered to the posterior peritoneum. The uterus and left ovary were intact, while the right ovary showed a smooth wall cyst of $2.5 \mathrm{~cm}$ and a solid para-ovaric mass of $5.5 \mathrm{~cm}$. Histologically, the tumor was composed of elongated cells, arranged in fascicles (Figs. 4 and 5). Mitotic figures were 17/50 HPF. Immunohistochemically CD117 (KIT), vimentin, CD34 and actin were 
Table II. Three cases of GIST presenting as a pelvic mass.

\begin{tabular}{|c|c|c|c|}
\hline & Case A (Belics) & Case B (Zighelboim) & Our case \\
\hline $\begin{array}{l}\text { Clinical } \\
\text { presentation }\end{array}$ & Abdominal mass and discomfort & $\begin{array}{l}\text { Lower abdominal pain; } \\
\text { dysuria; haematuria }\end{array}$ & $\begin{array}{l}\text { Increase of abdominal } \\
\text { circumference }\end{array}$ \\
\hline $\begin{array}{l}\text { Pelvic/vaginal } \\
\text { examination }\end{array}$ & $\begin{array}{l}\text { Large, compact, tense mass } \\
\text { extending above the umbilicus }\end{array}$ & $\begin{array}{l}\text { Left adnexal fullness; pelvic } \\
\text { mass extending from the } \\
\text { midline to the left lower } \\
\text { quadrant }\end{array}$ & $\begin{array}{l}\text { Large and compact mass } \\
\text { extending to the } \\
\text { periumbilicus area }\end{array}$ \\
\hline $\begin{array}{l}\text { Trans-vaginal/ } \\
\text { trans-abdominal } \\
\text { ultrasound }\end{array}$ & $\begin{array}{l}\text { Right-sided, well-circumscribed } \\
\text { bordered, mass containing dense } \\
\text { fluid; no ascites and no } \\
\text { metastasis }\end{array}$ & $\begin{array}{l}\text { Multiple confluent echogenic } \\
\text { masses throughout the pelvis, } \\
\text { moderately vascularized; } \\
\text { acites }\end{array}$ & $\begin{array}{l}\text { Heterogeneous and vascularized } \\
\text { mass; predominantly solid } \\
\text { containing extension bordering the } \\
\text { umbilicus; ovaries not visualized; } \\
\text { uterus displaced anteriorly; no } \\
\text { ascites and no metastasis }\end{array}$ \\
\hline
\end{tabular}

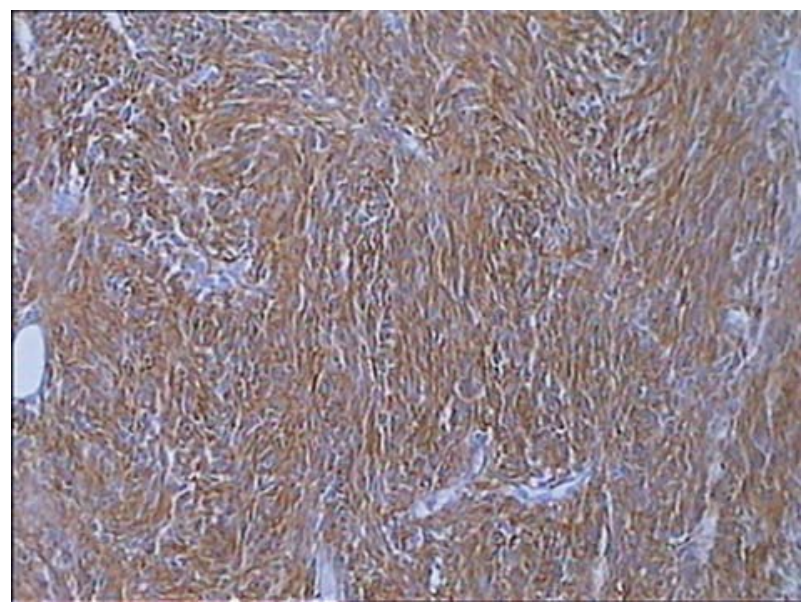

Figure 4. Diffuse, strong cytoplasmic immunopositivity for KIT (CD117).

positive while inhibin, calretinin, CD31 and desmin were negative. High-grade GIST was diagnosed. According to proposed guidelines which use combinations of tumor size and mitotic count to define risk, the tumor displayed morphological features of high risk (5). The patient had an uncomplicated postoperative course and was referred to the oncologist for suitable treatment.

\section{Discussion}

Gastrointestinal stromal tumor is the most frequent nonepithelial tumor occurring in the stomach and small bowel. The confusion and controversy surrounding this tumor are related to its enigmatic origin and difficulty in identifying reliable prognostic criteria. Tumors phenotypically identical to GISTs occur as primary tumors in the omentum and mesentery. The occurrence of CD117-positive tumors outside the gastrointestinal tract militates against an origin of these tumors exclusively from the interstitial cells of Cajal, which

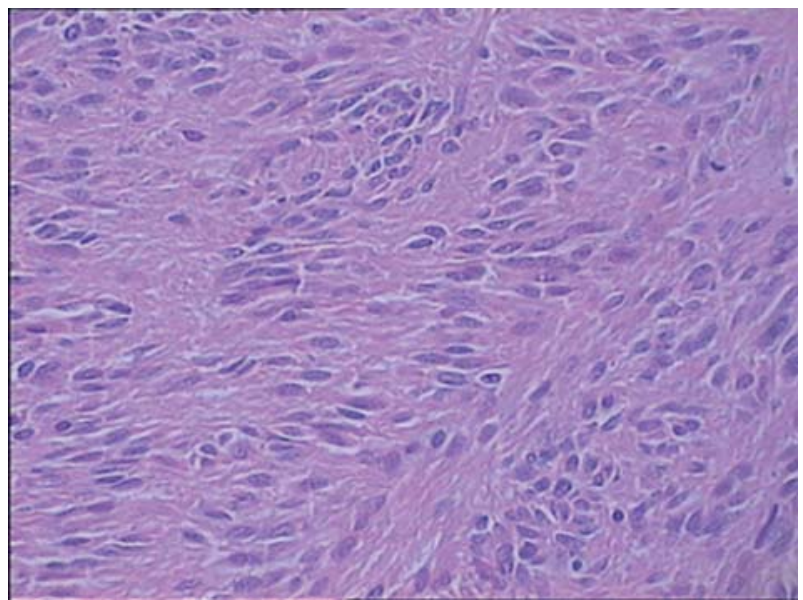

Figure 5. GIST is composed of uniform eosinophilic cells with ovoid nuclei arranged in fascicles.

are located between the myenteric plexus and smooth muscle cells of the gastrointestinal wall (10).

In the past, GISTs were considered to be smooth muscle in origin, but studies have shown a more complex picture with evidence of smooth muscle and neural differentiation, dual smooth muscle and neuronal differentiation, or no differentiation (undifferentiated mesenchyme). GISTs represent a subset of gastrointestinal mesenchymal tumors that include benign and malignant variants. Generally, GISTs with malignant behaviour are identified by increased mitotic activity and large tumor size. Currently lesions that are $\leq 2 \mathrm{~cm}$ and which are $<5$ mitoses $/ 50$ high power fields are thought to have lower malignant and metastatic potential. However, small tumors with low mitotic activity may still metastasize (11).

In the past, these tumors were classified as submucosal tumors (SMTs) given that they are of either muscular or neural derivation. It has become clearer that GISTs cannot be placed in any of these groups. This conclusion has been reached on the basis of electron microscopic and immunohistochemical 
tests. GISTs, in $\sim 95 \%$ of cases stain positively for the protein CD117, while other SMTs do not.

The preoperative diagnosis of GISTs is uncommon, due to their rarity and different modes of presentation as well as the lack of distinguishing characteristics on imaging studies.

On ultrasound imaging, GISTs exibit a variety of features that lack a typical pattern. These include hyperechoic central areas due to myxoid degeneration or the formation of microcysts within the mass. Usually there is no acoustic shadowing as calcific degeneration is rare. GISTs may also appear as large hypoechoic masses, often surrounded by a peripheral rim of residual echogenic parenchyma. Hypoechoic or anechoic regions within the tumor are related to areas of hemorrhagic necrosis and colliquation. In these cases low cellularity and abundant interstitial material may give the impression of a dense fluid (12).

GISTs are very rare and only a few cases among young gynaecological patients have been reported $(11,13)$ (Table II). Belics et al found a GIST presenting as an anteuterine pelvic mass, so they concluded that, as for mature cystic teratoma, a mass presenting anteriorly to the uterus is suspected of being a non-gynaecological pelvic tumor (13). In our case, however, the mass was posterior to the uterus and fixed in the pelvis. Moreover, the large abdominal circumference, its identification on the gynaecologic examination and the location of the mass, suggests an ovarian tumor. Therefore, our case indicates that a GIST may present itself as a retro-uterine mass as well. This finding explains the relevance of differential diagnosis of a pelvic mass, so that the possibility of non-gynecological tumors need to be considered.

\section{References}

1. Miettinen M, Sarlomo-Rikala M, Lasoto J, et al: Gastrointestinal stromal tumors: recent advances in understanding of their pathology. Hum Pathol 30: 1213-1220, 1999.

2. Burkill GJ, Badran M, Al-Muderis O, et al: Malignant gastrointestinal stromal tumor: distribution, imaging features, and pattern of metastatic spread. Radiology 226: 527-532, 2003.

3. Dematteo RP, Heinrich MC, El-Rifai WM and Demetri G: Clinical management of gastrointestinal stromal tumors: before and after STI-571. Hum Pathol 33: 466-477, 2002.
4. Kindblom LG, Remotti HE, Aldenborg F, et al: Gastrointestinal pacemaker cell tumor (GIPACT): Gastrointestinal stromal tumors show phenotypic characteristics of the interstitial cells of Cajal. Am J Pathol 152: 1259-1269, 1998.

5. Fletcher C, Berman J, Corless C, Gorstein F, et al: Diagnosis of gastrointestinal stromal tumors: a consensus approach. Hum Pathol 33: 459-465, 2002.

6. Emory TS, Sobin LH, Lukes L, et al: Prognosis of gastrointestinal smooth muscle (stromal) tumors: dependence on anatomic site. Am J Surg Pathol 23: 82-87, 1999.

7. Miettinen M, Sarlomo-Rikala M, Sobin LH, et al: Esophageal stromal tumor: a clinicopathologic, immunohistochemical and molecular genetic study of 17 cases and comparison with esophageal leiomyomas and leiomyosarcomas. Am J Surg Pathol 24: 211-222, 2000

8. O'Leary T and Berman JJ: Gastrointestinal stromal tumors: answers and questions. Hum Pathol 3: 456-458, 2002.

9. Dei Tos AP: The reappraisal of gastrointestinal stromal tumors: from Stout to the Kit revolution. Virchows Arch 442: 421-428, 2003.

10. Miettinen M, Monihan JM, Sarlomo-Rikala M, et al: Gastrointestinal stromal tumors/smooth muscle tumors (GISTs) primary in the omentum and mesentery: clinicopathologic and immunohistochemical study of 26 cases. Am J Surg Pathol 23: 1109-1118, 1999.

11. Zighelboim I, Henao G, Kunda A, Gutierrez C and Edwards C: Gastrointestinal stromal tumor presenting as a pelvic mass. Gynecol Oncol 91: 630-635, 2003.

12. Pinto V, Ingravallo G, Cicinelli E, et al: Gastrointestinal stromal tumors mimicking gynecological masses on ultrasound: a report of two cases. Ultrasound Obstet Gynecol 30: 359-361, 2007.

13. Belics Z, Csapò Z, Szabò I, Pàpay J, et al: Large gastrointestinal stromal tumor presenting as an ovarian tumor: a case report. J Reprod Med 48: 655-658, 2003. 